\title{
Study of Transmission Line Boundary Protection Using a Multilayer Perceptron Neural Network with Back Propagation and Wavelet Transform
}

\author{
Daniel Okojie $^{1}$, Linus Idoko ${ }^{2, *} \mathbb{C}$, Daniel Herbert ${ }^{1}\left(\mathbb{D}\right.$ and Agha Nnachi ${ }^{1}$ \\ 1 Department of Electrical Engineering, Emalahleni Campus, Tshwane University of Technology, \\ Emalahleni 1034, South Africa; deokojie@gmail.com (D.O.); herbert.danielr@gmail.com (D.H.); \\ nnachiaf@tut.ac.za (A.N.) \\ 2 Department of Electronic \& Computer Engineering, Veritas University, Bwari, Abuja 900001, Nigeria \\ * Correspondence: linus.idoko@yahoo.co.uk
}

check for updates

Citation: Okojie, D.; Idoko, L.; Herbert, D.; Nnachi, A. Study of Transmission Line Boundary Protection Using a Multilayer Perceptron Neural Network with Back Propagation and Wavelet Transform. Appl. Syst. Innov. 2021, 4, 95. https://doi.org/10.3390/ asi4040095

Academic Editor: Ludovico Minati

Received: 18 September 2021

Accepted: 18 November 2021

Published: 24 November 2021

Publisher's Note: MDPI stays neutral with regard to jurisdictional claims in published maps and institutional affiliations.

Copyright: (c) 2021 by the authors. Licensee MDPI, Basel, Switzerland. This article is an open access article distributed under the terms and conditions of the Creative Commons Attribution (CC BY) license (https:// creativecommons.org/licenses/by/ $4.0 /)$.

\begin{abstract}
Protection schemes are usually implemented in the planning of transmission line operations. These schemes are expected to protect not only the network of transmission lines but also the entire power systems network during fault conditions. However, it is often a challenge for these schemes to differentiate accurately between various fault locations. This study analyses the deficiencies identified in existing protection schemes and investigates a different method that proposes to overcome these shortcomings. The proposed scheme operates by performing a wavelet transform on the faultgenerated signal, which reduces the signal into frequency components. These components are then used as the input data for a multilayer perceptron neural network with backpropagation that can classify between different fault locations in the system. The study uses the transient signal generated during fault conditions to identify faults. The scientific research paradigm was adopted for the study. It also adopted the deduction research approach as it requires data collection via simulation using the Simscape electrical sub-program of Simulink within Matrix laboratory (MATLAB). The outcome of the study shows that the simulation correctly classifies $70.59 \%$ of the faults when tested. This implies that the majority of the faults can be detected and accurately isolated using boundary protection of transmission lines with the help of wavelet transforms and a neural network. The outcome also shows that more accurate fault identification and classification are achievable by using neural network than by the conventional system currently in use.
\end{abstract}

Keywords: neural network; wavelet transform; signal processing; backpropagation; multilayer perceptron; fault detection

\section{Introduction}

During the early years of electricity usage, local communities generated their electricity on a small scale to provide power for lighting and heat utilities. However, as communities grew into towns, and towns grew into cities, the demand for electricity also grew at a steady rate. This demand resulted in the construction of large generating stations away from cities and closer to sources of fuel. As a result of the more isolated locations of the generation stations, a means to convey the power generated to the consumer becomes a necessity. To achieve this, transmission lines were constructed to deliver the power from the generation station to the distribution center nearest to the consumer at a high voltage. Unfortunately, these lines are not perfect and are susceptible to faults that can cause high voltage and current spikes within the system. If these spikes are permitted to travel to either the generating station or the consumer, severe damage to equipment will occur [1,2]. Protection against faults is of great importance [3,4]. Any interruption across a transmission line will spread from one point to another across the network [5].

To protect against these faults, protective schemes are implemented along the entire length of the transmission network. These schemes consist of components that detect fault 
conditions and disconnect the faulted area from the rest of the network. At present, there are two types of protection schemes in use: unit and non-unit protection. Unit protection uses information gathered from both ends of the transmission line, resulting in costly communication links at either end. These communication links cannot be guaranteed to maintain contact at all times, as every communication network is influenced by external factors [6]. Non-unit protection schemes only use information gathered from a single end of the transmission line; thus, no communication network is needed $[7,8]$. However, these systems cannot detect faults in the overlapping areas of protection on the transmission line [6]. According to Mehta, currently, the solution in place to overcome this is backup protection, resulting in an additional cost for the scheme in the form of extra equipment [1].

This study focuses on a different method of non-unit protection. In this study, the boundary protection of transmission lines using wavelet transforms and a neural network was investigated. The proposed technique uses the transient signal generated during fault conditions to identify faults $[7,9,10]$. The fault signal is broken down into the frequency components using a wavelet transform, and the resultant signals are used by a neural network to classify the fault location according to the faulted line [11-13]. With traditional methods of fault detection, distortions in relations between voltage and current phasors may cause false tripping [11,14]. By using a neural network, more accurate fault identification and classification are achieved than with systems currently in use [12,14]. A neural network was found to be the best form of artificial intelligence for this application. The specific type of neural network is a multilayer perceptron (MLP) with backpropagation. This network uses multiple layers of classification to sort the provided information and backpropagation to learn from any error value present at the end of the layer set [15]. The reason behind this choice of neural network is that the information available to create such a network is easily available and the creation of the network is not as complex as that of an adaptive resonance theory network (ART) [11].

Neural networks are usually grouped in layers with neurons or nodes linking varying layers via an activation function. The input layer is the point at which patterns or data are introduced into the network. These patterns or data travels via weighted connections to the hidden layer after which they are processed as the network output at the output layer $[16,17]$.

\subsection{Boundary Protection Background}

In conventional protection systems, an area on either side of a busbar exists where the time difference between the initial fault and its reflection is too small for the system to detect and interpret correctly [7]. This may result in incorrect fault operations or failure to operate completely. In Figure 1, the relay is set to protect lines $2-3$. When a fault occurs on the line, the transient voltage and current signals travel in both directions on the line. During the transient period, the signals encounter points of discontinuity where reflections and refractions of the signal occur that travel back to the relay. Taking into account that each busbar serves as a node for the connection of various power system components. It acts as a filter that removes high-frequency signals during fault conditions and conducts them to earth [11]. This characteristic of a busbar is known as bus capacitance. The transmission lines used in this project are balanced $\pi$-sections with lumped parameters [18]. As shown in Figure 1, a fault occurring at F1 or F4 will have the high-frequency component of the transient current signal shunted to earth through the capacitance. This results in the relay receiving a current fault signal with the high-frequency component removed and a full spectrum voltage signal [11]. However, if the fault occurs at F2 or F3, the signal does not pass through a bus before it reaches the relay and does not lose any of its frequency components for both the transient voltage and current signals [11]. Since the voltage is obtained at bus 2, using only the voltage signals, it is only possible to differentiate between fault F3 and F4, but not between fault F1 and F2. However, by combing the voltage and current signals, it becomes possible to protect the entire line [7]. 


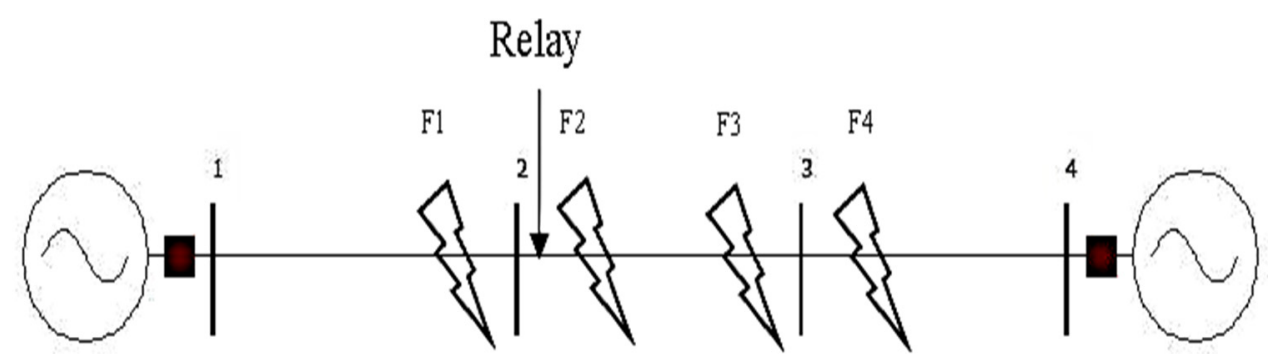

Figure 1. Simple multiline system.

\subsection{Signal Processing}

The importance of studies in the field of artificial intelligence and signal processing in the past two decades has been on a steady increase [19]. Uddin et al. [20] opined that signal processing has a broad range of applications and has transformed into a key element for the analysis of power systems. Signal processing methods are essential in an electrical power system as they offer the best analysis and characterization of signals that are to be investigated. In [21], signal processing refers to the science that enables the analysis of signals. According to a study by Germán-Salló and Strnad [22], fault detection with the help of signal processing techniques has attracted significant attention. The outcome of signal processing techniques is assessed via simulations. The techniques used for fault detection are divided into two key categories, signal processing-based and model-based approaches. Dastres and Soori [21] classified signal processing methods into five categories, as shown in Figure 2.

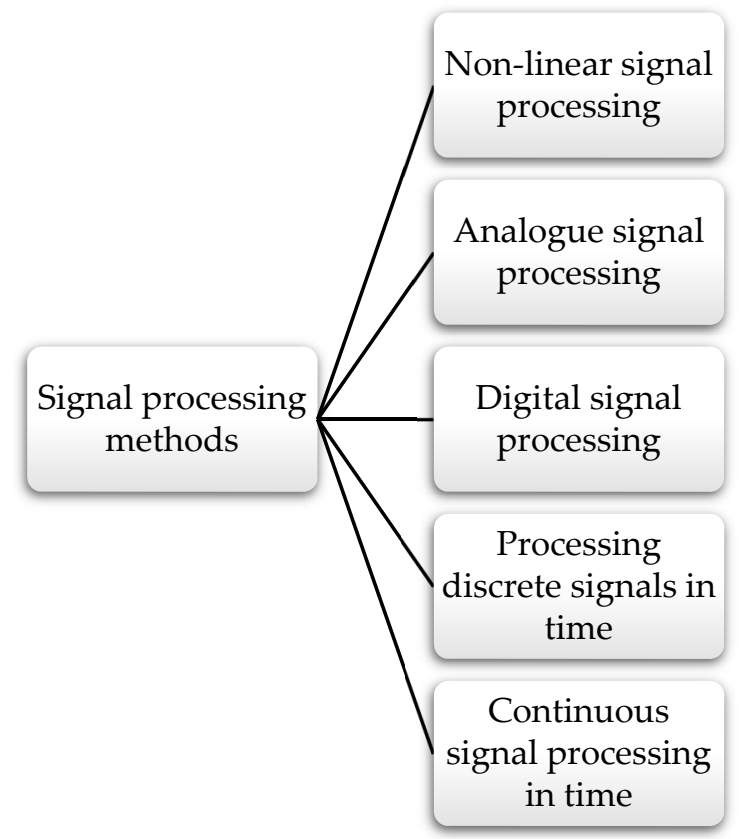

Figure 2. Classification of signal processing methods.

Among the numerous electrical power signal analysis techniques, this study adopted the wavelet transform and a multilayered perceptron neural network method.

\section{Wavelet Transforms}

A study carried out by Santoso et al. as well as that of Osman and Malik shows that, instead of the Fourier transform, wavelet transforms can be implemented in protection systems [23,24]. Since empirical mode decomposition (EMD) is not used in wavelet transform, mode mixing cannot occur. Where the Fourier transform requires all functions to be periodical, the wavelet transform requires a mother wavelet for all calculations to be based on. The selection of this mother wavelet defines the application of the wavelet trans- 
form [11]. A wavelet from the Daubichies family has been found to be the best suited for power systems transient analysis. This family of wavelet transforms allow for the analysis of fast decaying, short-duration transient signals [25]. A continuous wavelet transform $(C W T)$ of a signal $x(t)$ with mother wavelet $m(t)$ is defined by the equation:

$$
\operatorname{CWT}(g, h)=\frac{1}{\sqrt{g}} \int_{-\infty}^{\infty} x(t) m\left(\frac{t-h}{g}\right) d t
$$

where $g$ is the scale factor, $h$ is the translation factor, and $t$ is time; all three continuous.

In this application of a wavelet transform, it is not possible to use a CWT, as the faulted signal needs to be detected and resolved as it occurs and cannot be sampled over all time. To solve this problem, a discrete wavelet transform (DWT) is needed. This means that $g, h$, and $t$ in the previous equation need to be transformed to a discrete form. By implementing these changes to the CWT formula, a DWT can be represented by:

$$
\operatorname{DWT}(p, q)=\frac{1}{\sqrt{g_{o}} p} \sum_{k} x(k) m\left(\frac{k-q h_{o} g_{o} p}{g_{o}}\right)
$$

In Equation (2) the parameters $g$ and $h$ of Equation (1) were changed to be the functions of integers $p$ and $q$, respectively. $k$ is a variable integer and is equal to the sample number of an input signal [26-33].

One of the implementations of a DWT is known as multiresolution analysis. In Figure 3, the process of multiresolution analysis is shown. Firstly, the signal $x(n)$ is passed through both high and low pass filters. The outputs from each filter are then decimated by two, this gives the detailed (D) and approximate (A) coefficients at that level (L). The approximation obtained at level 1 is then used as the input signal for level 2, where the process is repeated. This carries on until the desired level is reached [11].

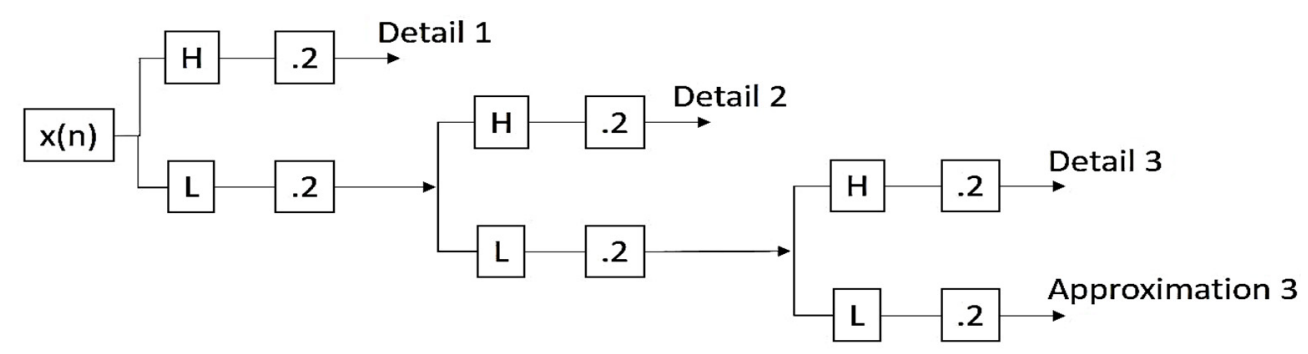

Figure 3. Multiresolution analysis.

Furthermore, in Figure 3, if the sampling rate is $\mathrm{H}$, the data obtained at D1 is between $\mathrm{H} / 4$ and $\mathrm{H} / 2$ of the signal frequency. D2 will obtain the information between $\mathrm{H} / 8$ and $\mathrm{H} / 4$, where $\mathrm{D} 3$ will obtain the information between $\mathrm{H} / 16$ and $\mathrm{H} / 8$. The remaining information between $\mathrm{H} / 16$ and 0 will be in A3. By decomposing a signal using this method, it is easier to process information found in different frequency ranges while still keeping the data in the same period. A sampling rate of $200 \mathrm{kHz}$ is used as it offers the best resolution against processing power.

\subsection{Neural Networks}

In traditional protection systems, hard calculation of certain electric values is used to set a threshold on the protective equipment. These thresholds are then continuously compared to actual readings obtained in real time. When an imbalance occurs in the system, the protective equipment is activated to isolate the fault. The determination of these threshold values requires a deep understanding of the transmission network and complex calculations to allow for protection against the worst fault conditions [11]. To avoid the problems posed by hard calculation of fault conditions, a soft protection method can be used. This soft method uses artificial intelligence in the form of a neural network to identify and classify numerous input signals and determine the best course of action 
for the protection of the system. The study of neural networks for the use of protection of transmission systems is not a new concept and has been ongoing for decades [34]. The use of neural network models finds application in several fields of research in engineering [35,36]. Kadam et al. [37] opined that machine learning offers a broad range of algorithms that can be adapted to help with fault detection. There are numerous types of machine learning and artificial intelligence structures to choose from when implementing an automated decisionmaking program. However, a neural network structure was chosen for this application as it is best suited for pattern recognition in data sets [38]. A typical example of neural network architecture is shown in Figure 4. The input data is accepted by the input layer and passed to the hidden layer. Data transformation does not occur in this layer. At the hidden layer, one or more transformations are carried out on the input data in order to generate an output close to the expected output. Furthermore, the final output is produced at the output layer and is usually compared with the expected output $[39,40]$.

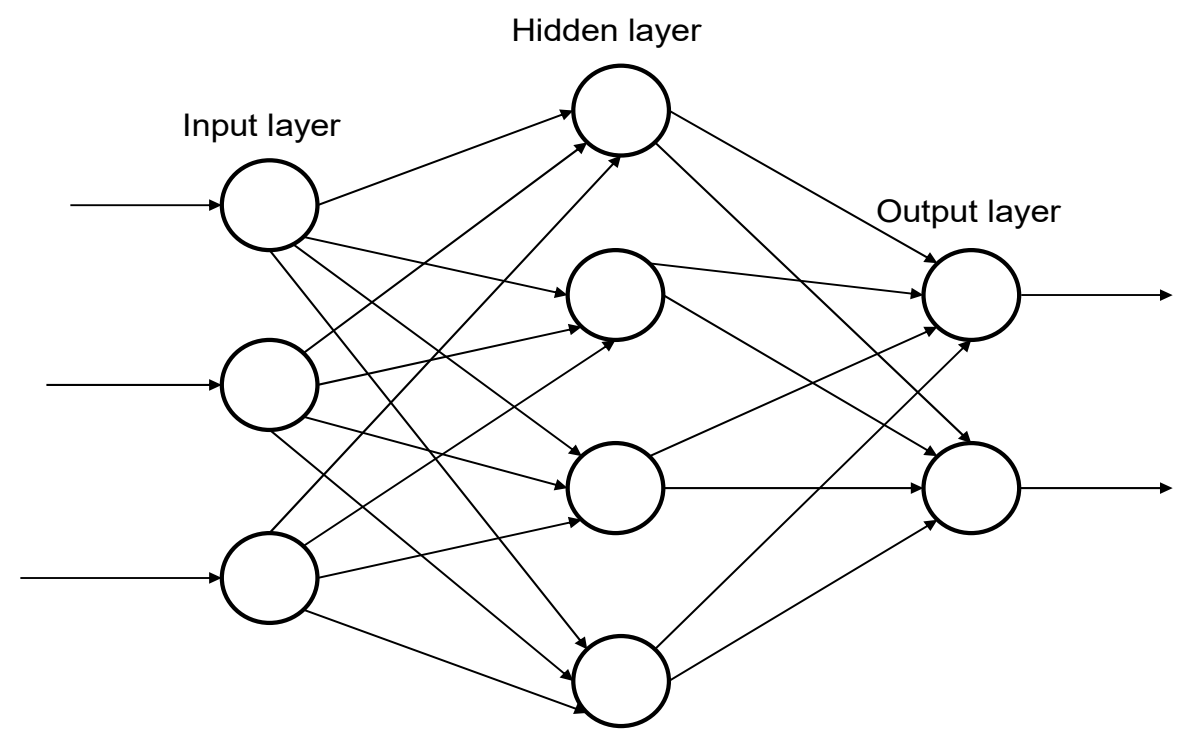

Figure 4. Neural network architecture.

\subsubsection{Adaptive Resonance Theory}

The adaptive resonance theory according to Silva et al. [41] is a learning theory that has inspired the architectures of several neural networks. This type of neural network operates by grouping similar data points together and spacing the groups apart according to their differences. When a new data point has to be classified, the network places the new data point within or near a group with similar characteristics [11]. It has the potential to perform quick, incremental, and steady supervised and unsupervised learning regarding a changing condition $[42,43]$.

Training for this type of neural network consists of two phases: supervised learning and unsupervised and reinforced learning. During unsupervised learning, the training data is used to create an initial grouping according to the similarity of the data points. These groupings and their spacing are then updated until there are no more changes in the grouping size or spacing $[11,44]$. Next is supervised learning, where an output is assigned to each group. This allows the network to separate the groupings according to the correct output. Once all the data points in a group provide the same output, it is considered homogenous and is no longer used for training. The size and position of the remaining groups are changed and reiterated through the training process. When all the groupings are homogenous, training is complete [11,45]. When a new data point falls near a grouping, it is allocated to that groupings output. However, if the data point falls in an area with no known outputs, fuzzy K-nearest neighbor $(\mathrm{K}-\mathrm{NN})$ is used to find the best fitting grouping [46]. This type of neural network is extremely powerful, as the number of groupings and their sizes are continuously updated throughout the training process [11]. 
This allows large data sets to be processed accurately with no incorrect labeling. A visual representation of how an ART network classifies data is presented in [12]. A simplified version of this is shown in Figure 5.

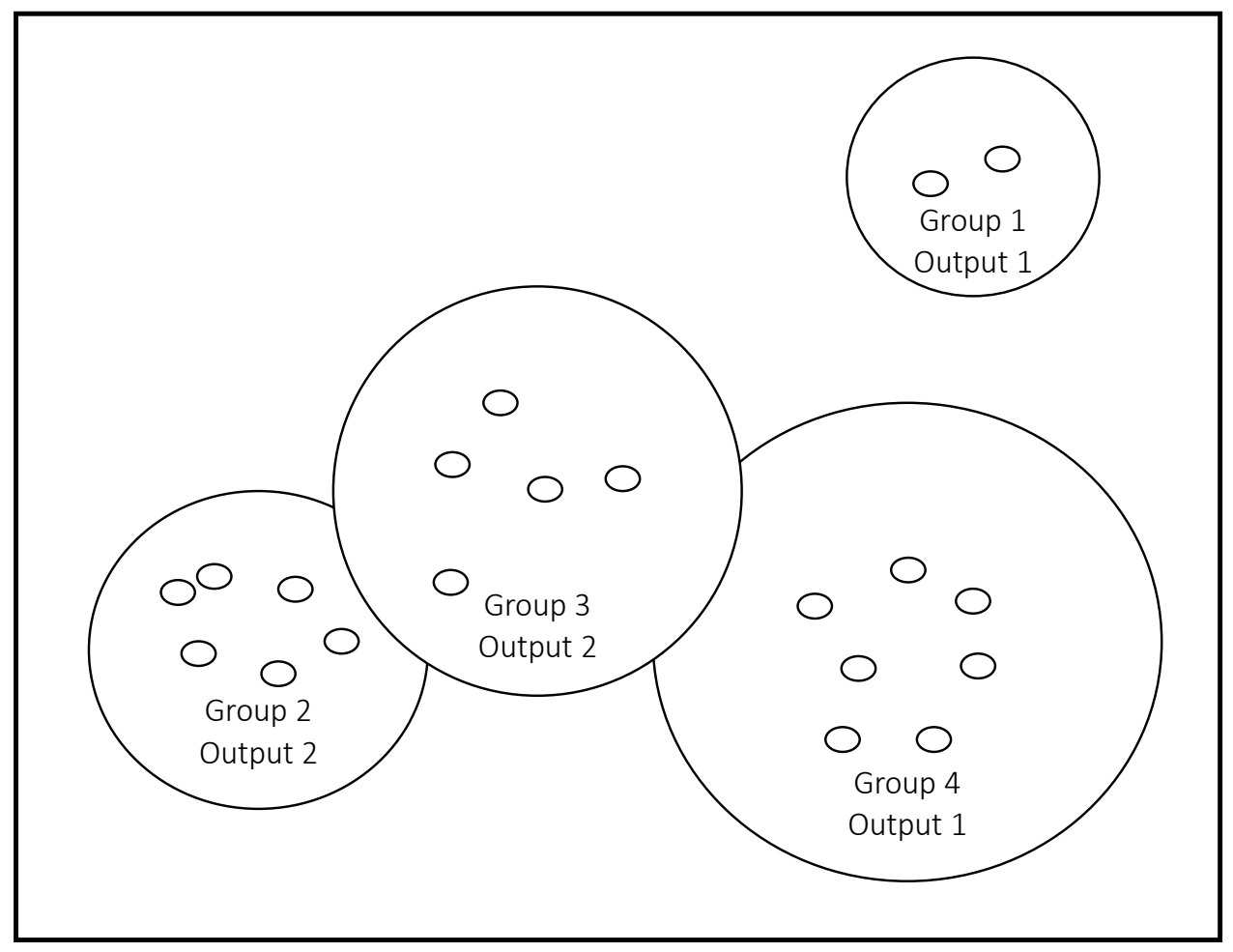

Figure 5. Representation of data grouping by an ART neural network.

\subsubsection{Multilayer Perceptron}

Many types of neural networks exist, but the one that has largely been used in power system studies is a multilayer perceptron (MLP) neural network with backpropagation (BP) for learning. This network is used since it is easier to design than other certain types. However, the problems faced with an MLP neural network include selecting the correct number of hidden neurons and the ability to handle large data sets. The purpose of neural network training is to ensure that the network allocates the input data to the correct hidden neurons (or nodes) and provides the correct output. Once training is complete, unsupervised learning commences. During this phase, the network is not told into which category to classify the data but rather attempts to group the data into nodes with similar characteristics. If the data runs through the entire hidden node group, it enters the backpropagation algorithm with an error value. This algorithm then assigns a weight to the error data and runs it through the network again for classification. The process is repeated until the error value reaches a preset allowable value [11,47-49].

In MATLAB, a built-in function called patternet is available. This function creates an MLP neural network with backpropagation according to user-specified layers and perceptrons [50,51]. Figure 5 shows a flow diagram of a simple two-layer MLP with perceptrons 4 and 3. This network uses five inputs to obtain two outputs and shows how the training algorithm factors into the network as shown in Figure 6. 


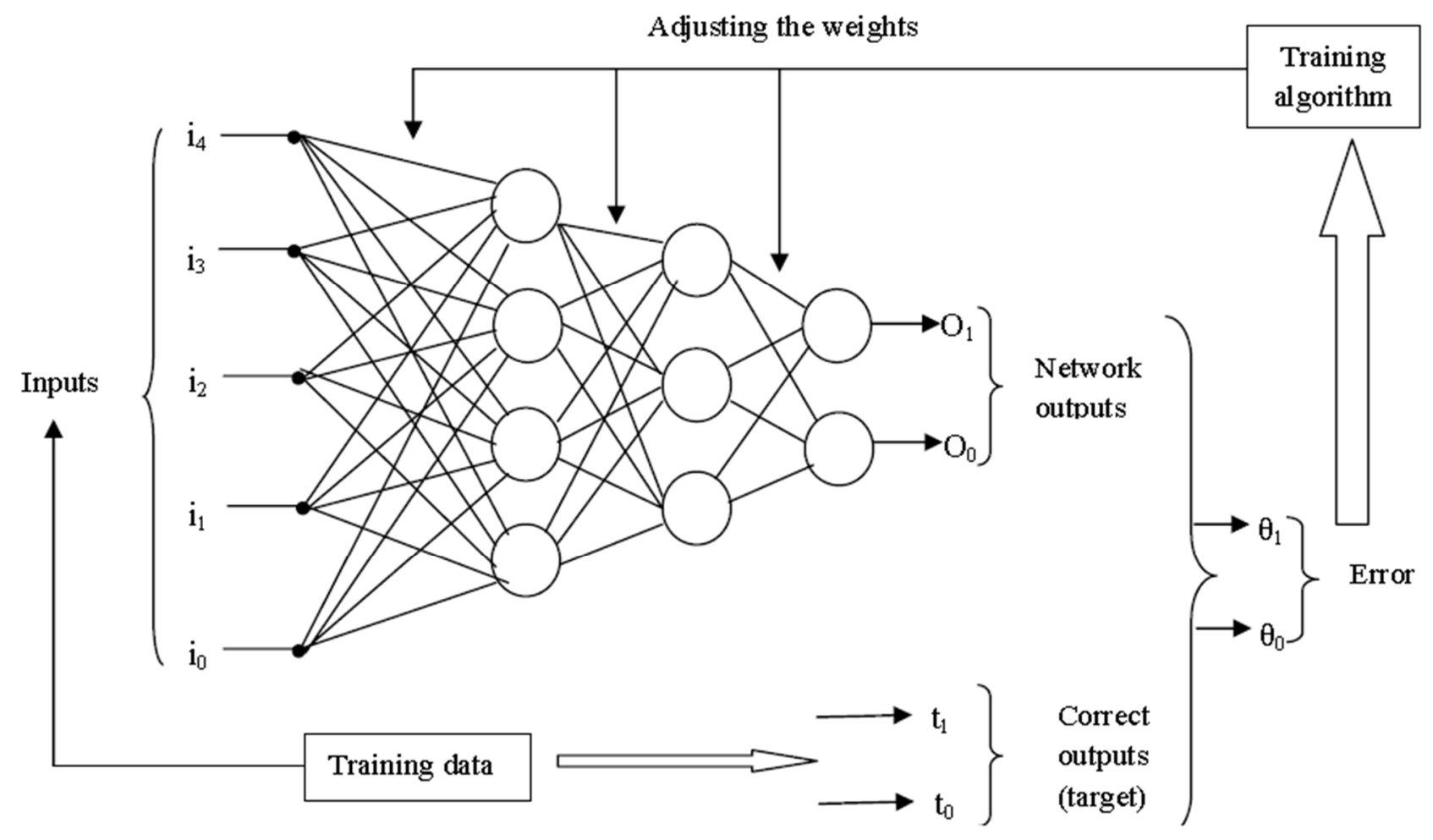

Figure 6. MLP architecture.

\subsection{Relevance of the Study}

The current methods of transmission line protection employed in most countries, including South Africa, either use costly communication links or backup protection systems to operate reliably. This study aims to provide further information and reassurance on current research suggesting that boundary protection using non-unit information is a viable replacement of unit protection and an improvement on non-unit protection systems. One of the biggest benefits of a theoretical study before practical implementation is that most scenarios can be tested without the possibility of causing damage to expensive switching and protection equipment if the system were to fail in its operation.

\section{Materials and Methods}

Four (4) major research paradigms exist: positivist/postpositivist, interpretivist/ constructivist, transforming, and pragmatic. The positivist/postpositivist, also referred to as scientific research paradigm, was adopted for this study. This is because the study is experimental [52]. The deduction research approach was also adopted for the study as it requires a quantitative research method [53,54]. The quantitative research method is made of three major research techniques, namely field experiments, simulation, and surveys. The simulation technique was adopted for the study. Data gathering was achieved via simulation using the Simscape electrical sub-program of Simulink within MATLAB.

\subsection{Simulation Design}

A sub-program of the Simulink software within MATLAB was used for the simulation of the transmission line. The output of the simulation is then used as input into a MATLAB program for pre-processing before a neural network is used for fault classification. The explanation of each of the components involved and the flow chart of the neural network is provided below. 


\subsubsection{Transient Fault Signal}

In order to simulate a transmission line with various faults, the Simscape Electrical sub-program of Simulink was used. With this software, it is possible to simulate threephase transmission lines and a variety of faults at chosen locations. After running the simulation, the fault is introduced at a specific time, and Simscape puts out the transient waveforms in a format readable by MATLAB scripts. To simulate busbars under fault conditions, a three-phase load to ground with a pure capacitive value was used, these loads were rated at $100 \mathrm{VAr}$. Each transmission line had a length of $100 \mathrm{~km}$ and a frequency of $50 \mathrm{~Hz}$. Although in Figure 1 a relay is shown in the single line diagram, for simulation purposes, no operational relay was used to isolate the transmission line. In place of the relay, a three-phase voltage and current measuring device was used to measure the transient signals as they would be experienced by the relay pick-up in practice.

For the fault, a three-phase fault block was used. This block allows for a combination of all the fault types to be simulated and the reaction of the system monitored. Both the ground resistance $\left(R_{g}\right)$ and fault resistance $\left(R_{f}\right)$ were left at their default values of $0.01 \Omega$ and $0.001 \Omega$, respectively. The neural network created in MATLAB, its flow chart, and the model used in Simscape to simulate the three-phase faults on the transmission lines are as shown in Figures 7-9 respectively. Located at each end is a three-phase source with phase-to-phase voltage of $500 \mathrm{kV}$, with three transmission lines as connections. Between each transmission line is a three-phase load to the ground. These loads represent busbars under fault conditions as they will also conduct any high-frequency components to the ground. Located between lines 1 and 2 at the same location as the relay is a three-phase voltage and current measuring device. From this device, the current is measured and written to the workspace for further processing.

\subsubsection{Wavelet Transforms}

The transient fault signal obtained from the simulation program is used as input into a sub-program written in MatLab. This program uses the wavelet toolbox within MatLab to perform a five-level decomposition of the sample signal with Daubichie's wavelet family as the mother wavelet. By decomposing the signal into five frequency bands, a better image of the fault can be obtained by studying the various waves. The wavelet transform of each phase is obtained with the MatLab command wavedec. This command allows a five-level decomposition to be made using Daubichies's db5 as the mother wavelet.

\subsubsection{Neural Network}

The specific type of neural network used in this simulation is a multilayer perceptron neural network, with backpropagation for learning. Backpropagation was adopted in the study instead of feedforward. This is because in [55], it provides us with a comprehensive understanding of how the entire behavior of the neural network changes with changing weights and biases. It aims to help with training the network. Inputs into the neural network are the six outputs from the wavelet transform of the transient signals. To train the network, known cases and the results are used to build a database for the network to refer new cases to. When training is complete, the network can classify new cases according to what has been learned already. The architecture of the neural network is three hidden layers with perceptron's 5, 10, and 5, respectively. This architecture was chosen as it produces the most accurate output and is the maximum that the available hardware can compute. A representation of the neural network produced by MATLAB is shown in Figure 7. To obtain the neural network in MATLAB, the Deep Learning (DL) toolbox was used. Available within the DL toolbox is a function to create a pattern recognition neural network called patternnet. In Figure 7, w represents weights while b represents biases. The figure represents the input and hidden and output layers of the neural network in MATLAB.

The flow chart of the neural network and the simulation of the transmission line system are shown in Figures 8 and 9, respectively. 


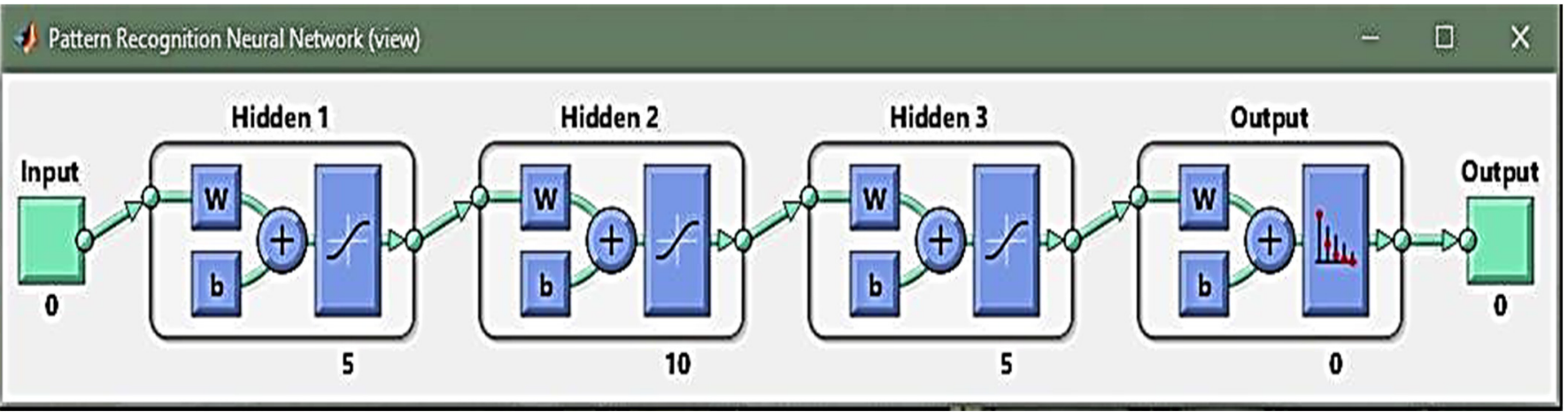

Figure 7. A neural network created in MATLAB.

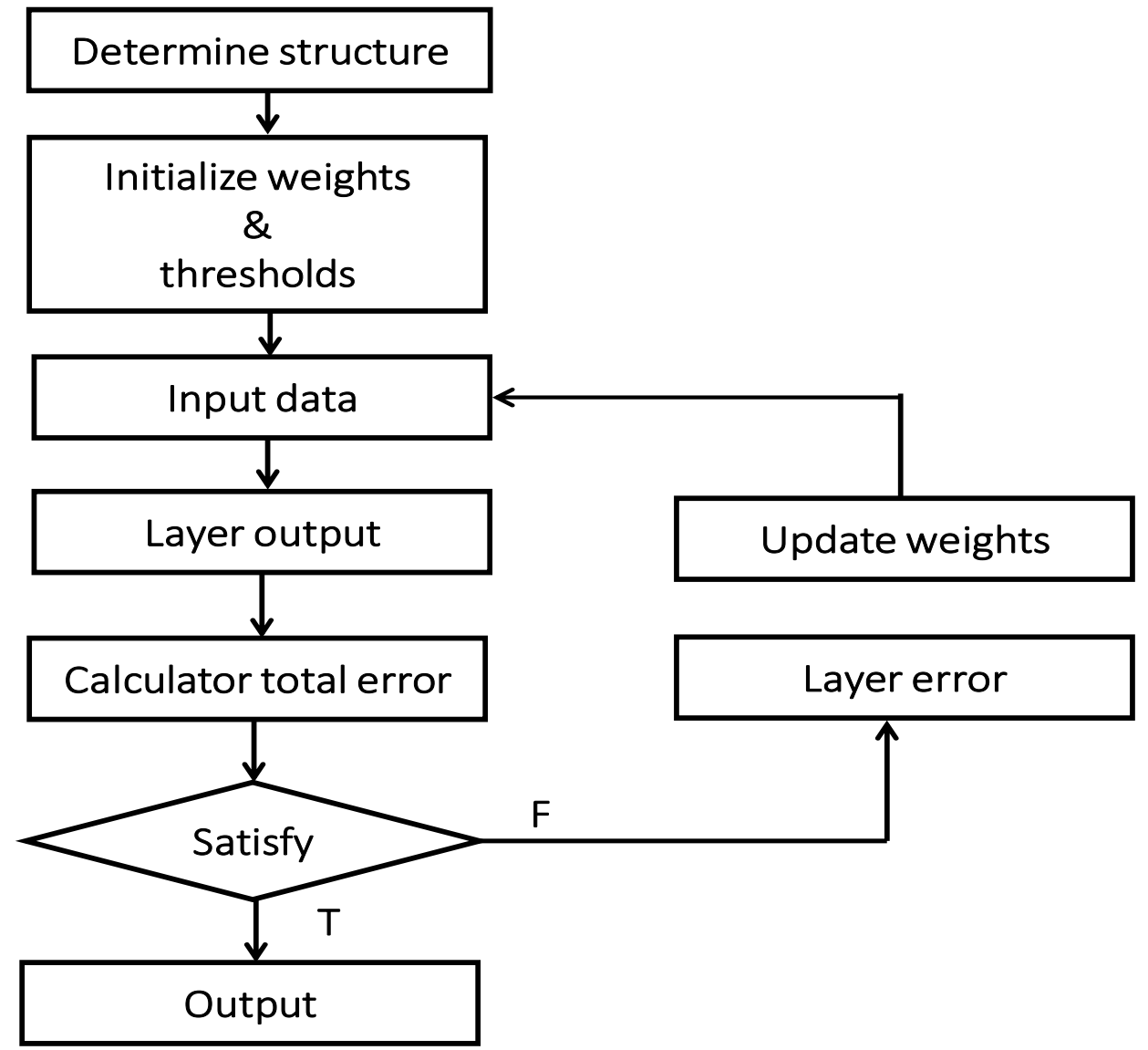

Figure 8. Flow chart of the neural network [56]. 


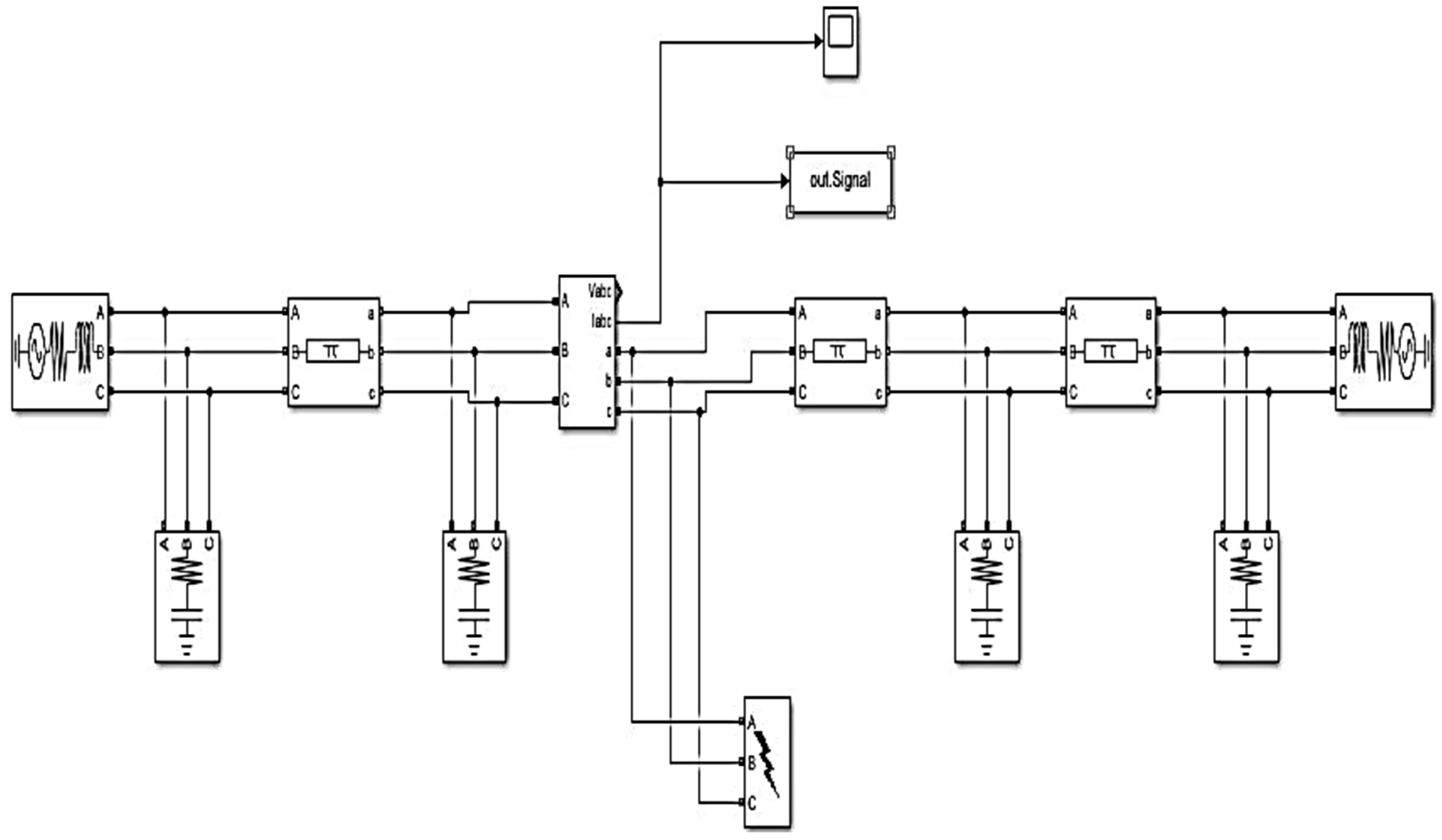

Figure 9. Simulation of the transmission line system. 


\section{Results}

\subsection{Simulation Results}

For training purposes, 44 different cases were simulated and classified under one of the three fault locations. To ensure sufficient training within the capabilities of the hardware available, the number of validation checks was set to 44 . A graph generated by the training tool to show the progress during neural network training is shown in Figure 10.

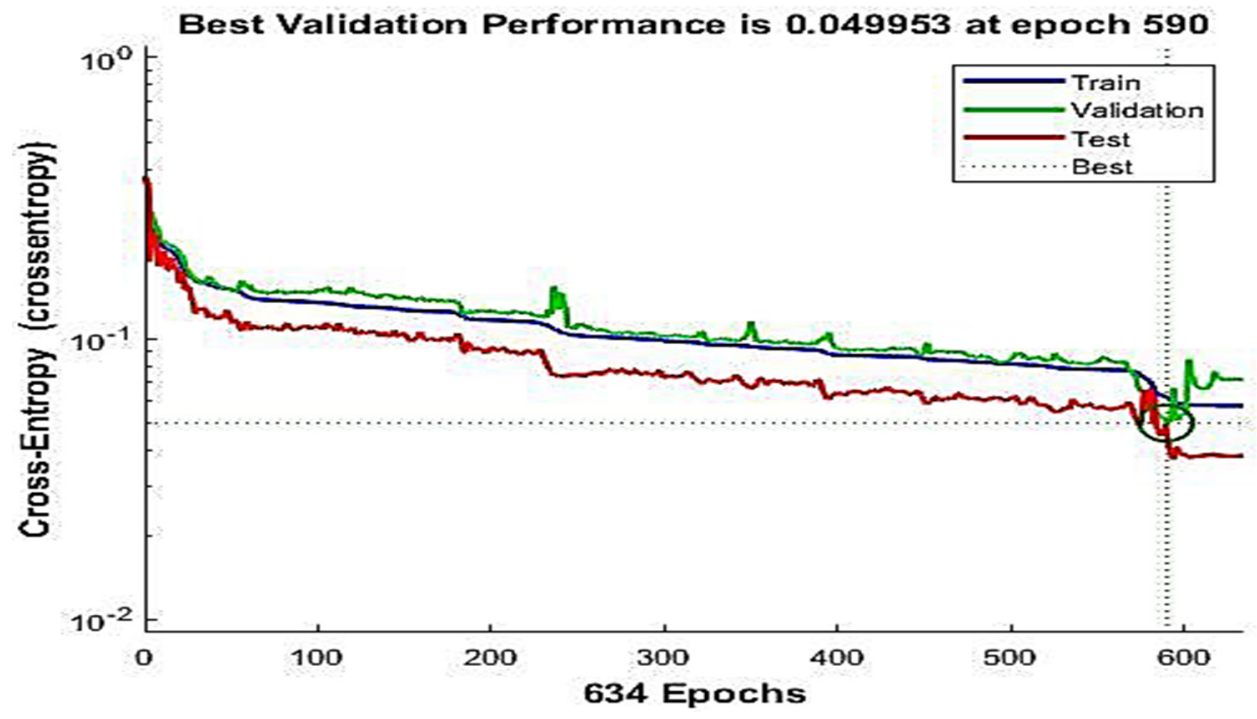

Figure 10. Graph of performance during training.

From Figure 9 it can be seen that the training completed 634 epochs before 44 consecutive correct validations were obtained. It is important to note that one epoch in terms of a neural network is when the entire training dataset is passed through the network once. After the dataset is passed forward and backward through the network, the initial weights are updated, and the process runs again. This cycle continues until one of the parameters within the training tool is met. At each of the four (4) fault locations, as shown in Figure 1, eleven (11) fault scenarios were created. These faults are shown in Table 1.

Table 1. Breakdown of the simulated faults.

\begin{tabular}{cll}
\hline Single-Phase-to-Ground & Double-Phase-to-Ground & Phase-to-Phase \\
\hline Phase A-Ground & Phase A-Phase B-Ground & Phase A-Phase B \\
Phase B-Ground & Phase A-Phase C-Ground & Phase A-Phase C \\
Phase C-Ground & Phase B-Phase C-Ground & Phase B-Phase C \\
\hline
\end{tabular}

Aside from the nine faults shown in Table 1, a fault between all three phases and all three phases to ground was simulated, bringing the total number of faults per location to eleven (11). For the phase-to-phase faults, a fault resistance of $0.001 \Omega$ was used, and for faults including a ground, the grounding resistance was set to $0.01 \Omega$. After a fivelevel wavelet decomposition was performed on each phase of the transient fault signal, 600,132 data points were obtained per fault. The network was then trained using these data points to classify fault locations. The signals generated from a single-phase-to-ground fault and double-phase-to-ground fault are as shown in Figures 11 and 12, respectively. These are examples of the transient signals used to train the neural network. These two graphs only show the wave shapes. 


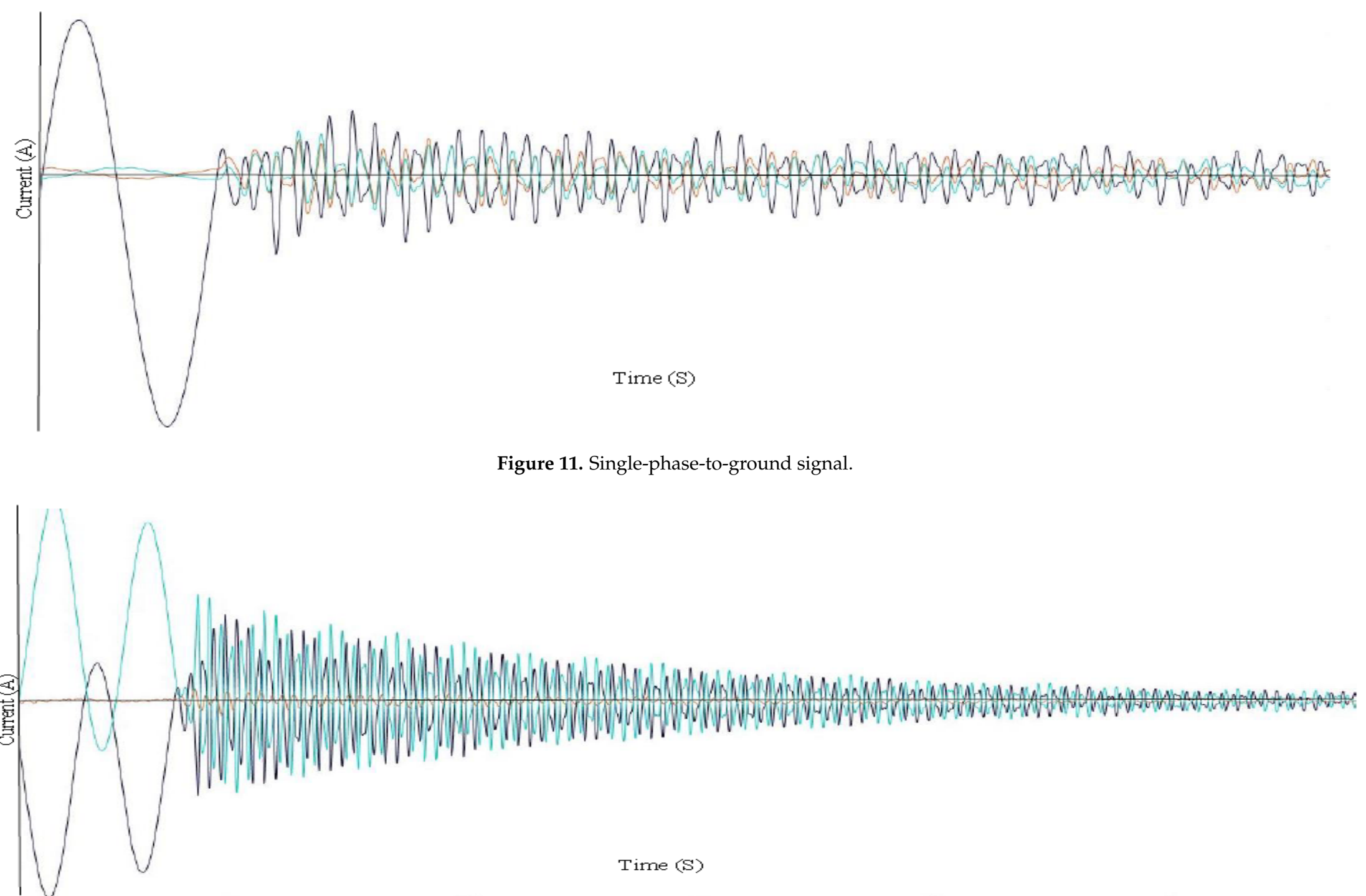

Figure 12. Double-phase-to-ground signal. 


\subsection{Accuracy of Neural Network}

To test the accuracy of the neural network, 34 faults were simulated at different fault locations and classified by the neural network. The result of the network was then compared to the fault location, and an accuracy rate was calculated to determine the viability of the system, see details in Table 2 .

Table 2. Results of the study.

\begin{tabular}{ccccc}
\hline \multirow{2}{*}{ Description } & \multicolumn{3}{c}{ Location } \\
\cline { 2 - 5 } & F1 & F2 & F3 & F4 \\
\hline Number of tests & 8 & 8 & 8 & 10 \\
Number correctly classified & 8 & 8 & 8 & 0 \\
Success rate (\%) & 100 & 100 & 100 & 0 \\
\hline
\end{tabular}

From Table 2 it may be observed that the network was able to correctly classify all the faults in locations F1, F2, and F3. However, at location F4, the network was unable to correctly classify the location. Each fault condition at location F4 was classified as a main line fault, which corresponds to a fault at location F2 or F3. This resulted in an overall success rate of $70.59 \%$. Since the requirement of the network was to correctly classify faults in the different boundaries of a multiline transmission network, it can be regarded as partly successful. The network was able to correctly classify both back line and main line faults. However, it was unable to correctly classify forward line faults and continuously classified forward line faults as main line faults.

\subsection{Simulating Different Parameters}

After testing was completed on the ability of the program to classify faults at different locations, further investigation was done on the effect that changes to certain simulation parameters have on the outcome.

\subsubsection{Different Line Lengths}

The line lengths were changed to 50,100, and $200 \mathrm{~km}$, and the simulation was run for each length. The fault was kept the same for each length, and the transient signal was classified by the neural network. In Figure 13, a comparison of the level five detail of phase A during phase $A$ and $C$ to ground fault on the main line for each length can be seen. Only a few of the faults were correctly classified when the lengths were changed to 50 and $200 \mathrm{~km}$. In Figure 12, it becomes clear why. By changing the length of the line, the wavelet transform of the current changes drastically, and the neural network is no longer able to classify it using the training data. A diagram that shows the comparison between the different line lengths is shown in Figure 13. 


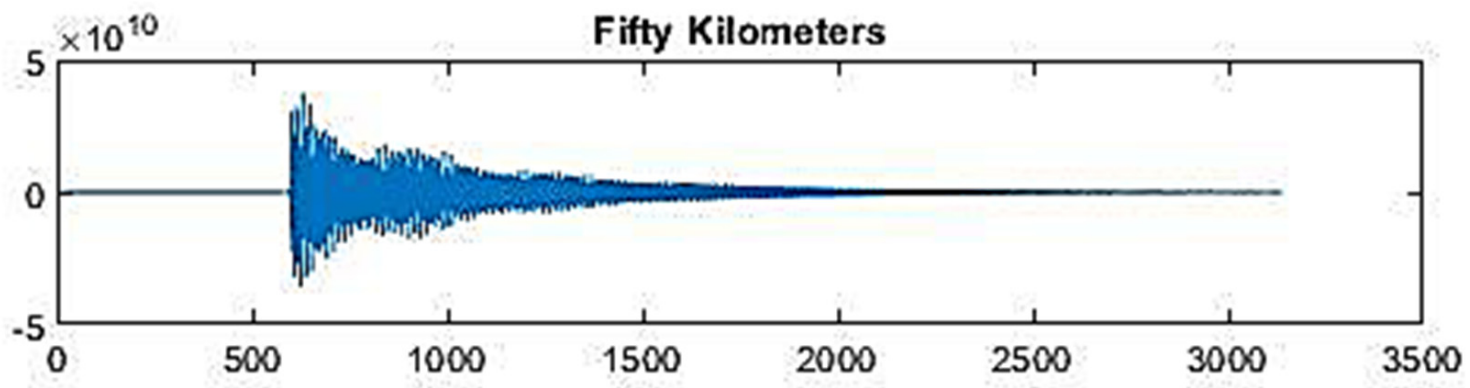

Hundred Kilometers
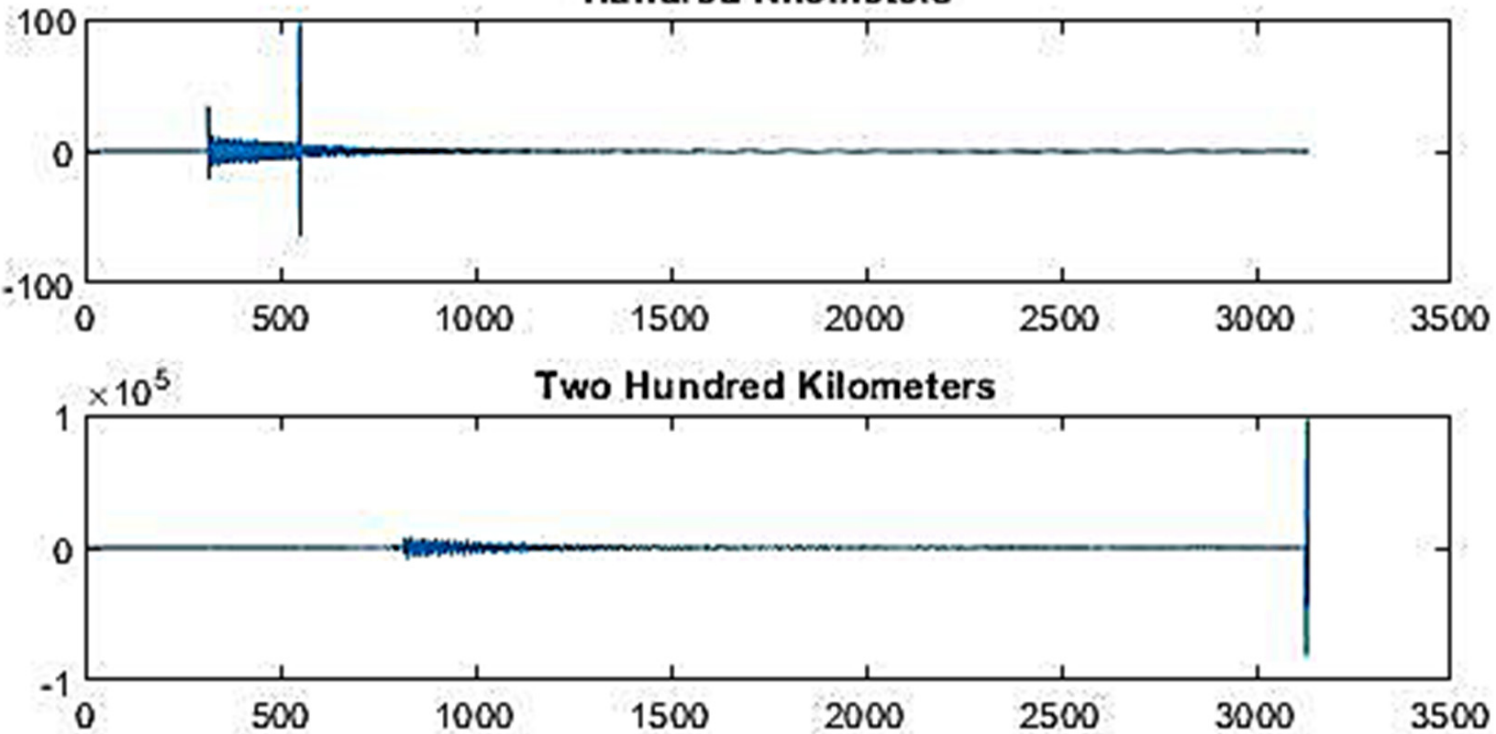

Figure 13. Comparison of different line lengths.

\subsubsection{Changes in Bus Capacitance}

As stated at the start of the study, a busbar is connected to various client equipment. This results in the busbar filtering high-frequency components of the transient signal. In the simulation, this was represented as a capacitive load to ground, and the capacitance left at a comparatively low value. However, no two busbars have precisely the same equipment connected. This results in different characteristics forming at each busbar under fault conditions and the filtering effect changing. To see the effect of a change on the capacitive load to ground on the fault current, the transmission line lengths were set to $100 \mathrm{~km}$ again, and the capacitance of each load increased by $20 \%$ and then $40 \%$ of the original value. In Figures 14-16, the effect of these changes can be seen. It is important to note that these figures only show the waveforms and not values. After obtaining the transient signal of the changed bus capacitance, it was classified by the trained network. The network was not able to correctly classify any of the faults. This is to be expected as it was never trained with data that includes different bus capacitances. 


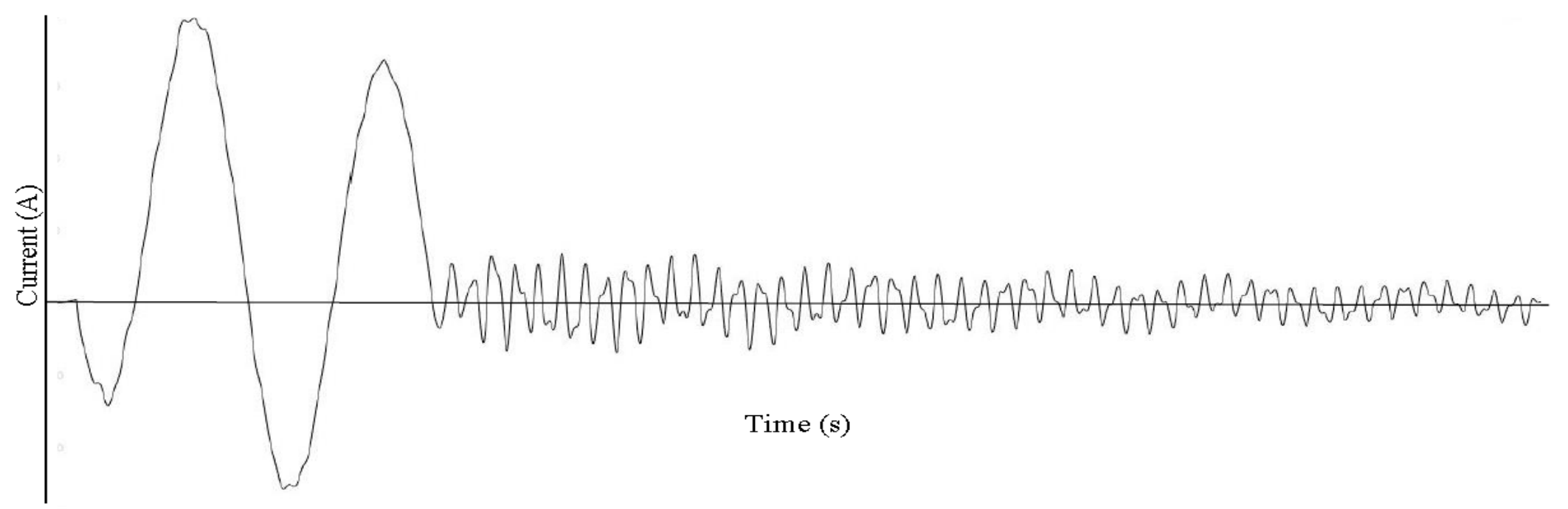

Figure 14. Normal bus capacitance.

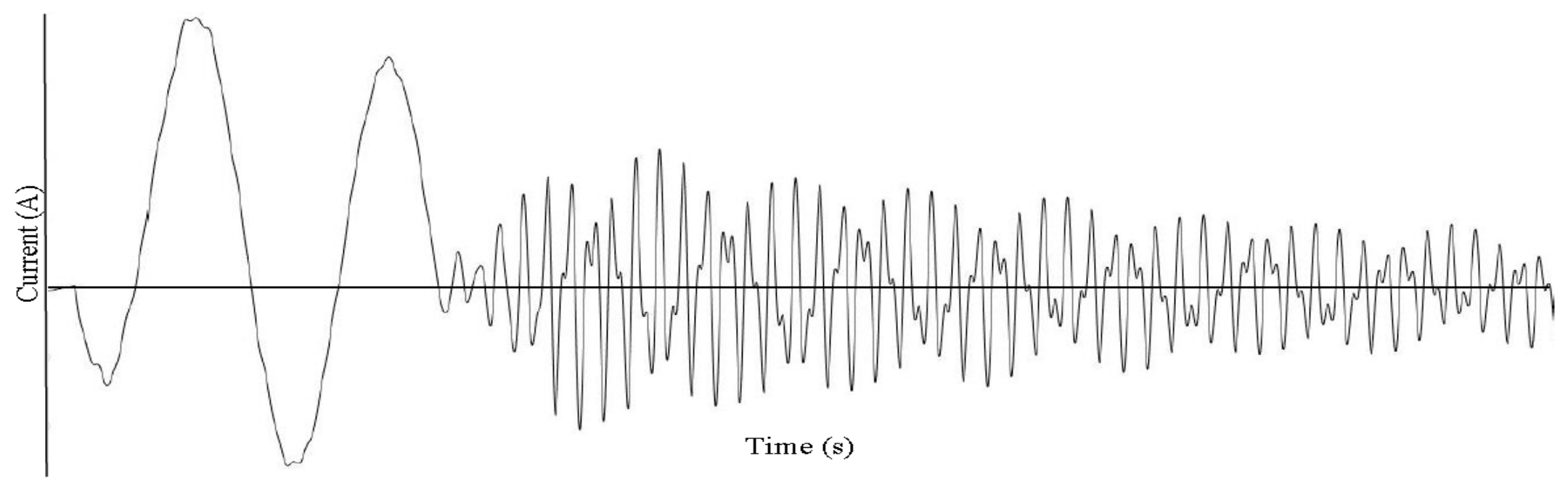

Figure 15. Bus capacitance increased by $20 \%$. 


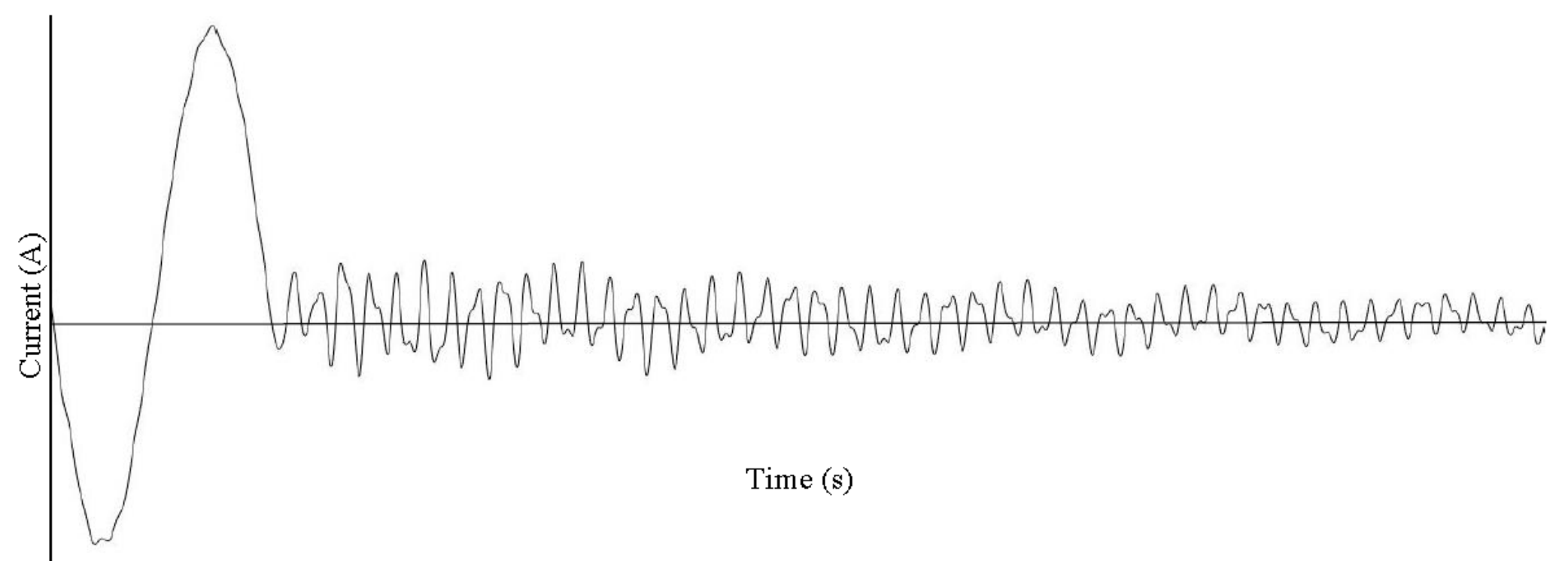

Figure 16. Bus capacitance increased by $40 \%$. 


\section{Conclusions}

The outcome of the study shows that the simulation correctly classifies $70.59 \%$ of the faults when tested. This implies that the majority of the faults can be detected and accurately isolated. Since the protective scheme was unable to identify and isolate all faults, it is proposed that further studies be conducted until the system is able to detect and isolate all faults. One of the causes of inaccuracy in this study is that only the current signals could be used. Using both voltage and current signals would provide a better chance of classifying all faults. A practical design is not shown or proposed in this study, but it is assumed that existing microprocessors can be trained with a neural network specific to certain transmission lines.

Author Contributions: Conceptualization, D.O., L.I., D.H. and A.N.; methodology, L.I., and D.O.; software, A.N., and D.O.; validation, D.O., A.N. and L.I.; formal analysis, D.H.; investigation, A.N.; resources, D.H.; writing—original draft preparation, A.N.; writing—review and editing, L.I. All authors have read and agreed to the published version of the manuscript.

Funding: This research received no external funding.

Institutional Review Board Statement: Not applicable.

Informed Consent Statement: Not applicable.

Data Availability Statement: Not applicable.

Conflicts of Interest: The authors declare no conflict of interests.

\section{Glossary}

Nomenclature

$\begin{array}{ll}\text { G } & \text { Scale factor } \\ h & \text { Translation factor } \\ p \& q & \text { Integers } \\ x & \text { Signal } \\ k & \text { Variable integer } \\ m & \text { Mother wavelet } \\ \text { H } & \text { Sample rate } \\ \text { D } & \text { Detailed coefficient } \\ \text { L } & \text { Level } \\ \text { R } & \text { Ground resistance } \\ \infty & \text { Infinity } \\ \text { Acronyms } & \\ \text { CWT } & \text { Continuous wavelet transform } \\ \text { DWT } & \text { Discreet wavelet transform } \\ \text { MATLAB } & \text { Matrix laboratory } \\ \text { MLP } & \text { Multilayer perceptron } \\ \text { ART } & \text { Adaptive resonance theory } \\ \text { NN } & \text { Neural network } \\ \text { K-NN } & \text { k-nearest neighbour } \\ \text { DL } & \text { Deep learning } \\ \text { EMD } & \text { Emperical modedecomposition } \\ \text { Subscripts } & \\ \text { g } & \text { Ground } \\ \text { f } & \text { Fault }\end{array}$




\section{References}

1. Mehta, V.K.; Mehta, R. Principles of Power System: Including Generation, Transmission, Distribution, Switchgear and Protection, 3rd ed.; S. Chand publishing: New Delhi, India, 2005.

2. Kavuma, C.; Sandoval, D.; de Dieu, H.K.J. Analysis of power generating plants and substations for increased Uganda's electricity grid access. AIMS Energy 2021, 9, 178-192. [CrossRef]

3. Akanto, J.M.; Hazari, M.R.; Mannan, M.A. LVRT and Stability Enhancement of Grid-Tied Wind Farm Using DFIG-Based Wind Turbine. Appl. Syst. Innov. 2021, 4, 33. [CrossRef]

4. Bertoldo, S.; Carosso, L.; Marchetta, E.; Paredes, M.; Allegretti, M. Feasibility Analysis of a LoRa-Based WSN Using Public Transport. Appl. Syst. Innov. 2018, 1, 49. [CrossRef]

5. Filho, M.F. Dynamical Networks Modelling Applied to Low Voltage Lines with Nonlinear Filters. Appl. Syst. Innov. 2020, 3, 1-22.

6. Glover, J.D.; Overbye, T.J.; Sarma, M.S. Power System Analysis E Design, 6th ed.; Cengage Learning: Boston, MA, USA, 2017.

7. Bo, Z.Q. A new non-communication protection technique for transmission lines. IEEE Trans. Power Deliv. 1998, 13, 1073-1078. [CrossRef]

8. $\quad$ Brice, G.J.; Mani, S.S.V.; Paul, K.; Milovanovic, S.; Eric, S.; Jinfeng, R.; Sarina, A.; Jesse, G. Integrated Smart Distribution RD E D Project Final Technical Report; Department of Energy: Pittsburgh, PA, USA; Morgantown, WV, USA, 2017.

9. Lin, X.N.; Bo, Z.Q.; Caunce, B.R.J.; Chin, N.F. Boundary protection using complex wavelet transform. In Proceedings of theSixth International Conference on Advances in Power System Control, Operation and Management-Proceedings APSCOM 2003, Hong Kong, China, 11-14 November 2003; pp. 744-749.

10. Bo, Z.Q.; Jiang, F.; Chen, Z.; Dong, X.Z.; Weller, G.; Redfern, M.A. Transient based protection for power transmission systems. In Proceedings of the 2000 IEEE Power Engineering Society, Conference Proceedings, Singapore, 23-27 January 2000; Volume 3, pp. 1832-1837.

11. Zhang, N.; Kezunovic, M. Transmission line boundary protection using wavelet transform and neural network. IEEE Trans. Power Deliv. 2007, 22, 859-869. [CrossRef]

12. Vasilic, S.; Kezunovic, M. Fuzzy ART neural network algorithm for classifying the power system faults. IEEE Trans. Power Deliv. 2005, 20, 1306-1314. [CrossRef]

13. Zhang, B.H.; Duan, J.D.; Ha, H.X.; Bo, Z.Q. Boundary protection, a new concept for extra high voltage transmission lines-Part II: Discriminative criterions and simulations. In Proceedings of the IEEE Power Engineering Society Transmission and Distribution Conference, Dalian, China, 18 August 2005; pp. 1-6.

14. Taft, J.D. Fault Intelligence: Distribution Grid Fault Detection and Classification. In Pacific Northwest National Laboratory, Richland; Department of Energy: Washington, DC, USA, 2017; p. 99352.

15. Poulton, M.M. Handbook of geophysical exploration: Seismic exploration. Handb. Geophys. Explor. Seism. Explor. 2001, 30, 1-335.

16. Panchal, S.; Mathew, M.; Dincer, I.; Agelin-Chaab, M.; Fraser, R.; Fowler, M. Thermal and electrical performance assessments of lithium-ion battery modules for an electric vehicle under actual drive cycles. Electr. Power Syst. Res. 2018, 163, 18-27. [CrossRef]

17. Panchal, S.; Dincer, I.; Agelin-Chaab, M.; Fraser, R.; Fowler, M. Design and simulation of a lithium-ion battery at large C-rates and varying boundary conditions through heat flux distributions. Measurement 2018, 116, 382-390. [CrossRef]

18. MathWorks. Implement three-phase transmission line section with lumped parameters. MathWorks Help Center. 2021. Available online: https://www.mathworks.com/help/physmod/sps/powersys/ref/threephasepisectionline.html (accessed on 6 September 2021).

19. Perić, Z.; Delić, V.; Stamenković, Z.; Pokrajac, D. Advanced Signal Processing and Adaptive Learning Methods. Comput. Intell. Neurosci. 2019, 2019, 1-2. [CrossRef]

20. Uddin, Z.; Ahmad, A.; Qamar, A.; Altaf, M. Recent advances of the signal processing techniques in future smart grids. Hum. -Cent. Comput. Inf. Sci. 2018, 8, 1-15. [CrossRef]

21. Dastres, R.; Soori, M. A Review in Advanced Digital Signal Processing Systems. Int. J. Electr. Comput. Eng. 2021, 15, 122-127.

22. Germán-Salló, Z.; Strnad, G. Signal processing methods in fault detection in manufacturing systems. In Proceedings of the 11th International Conference Interdisciplinarity in Engineering, INTER-ENG 2017, Tigus Mures, Romania, 5-6 October 2017; Volume 22, pp. 613-620.

23. Osman, A.H.; Malik, O.P. Transmission line distance protection based on wavelet transform. IEEE Trans. Power Deliv. 2004, 19, 515-523. [CrossRef]

24. Santoso, S.; Powers, E.J.; Grady, W.M.; Hofmann, P. Power quality assessment via wavelet transform analysis. IEEE Trans. Power Deliv. 1996, 9, 924-930. [CrossRef]

25. Kim, C.H.; Aggarwal, R. Wavelet transforms in power systems Part 1 general introduction to the wavelet transforms. Power Eng. J. 2000, 14, 81-88.

26. Ali, A.; Sheng-Chang, C.; Shah, M. Continuous wavelet transformation of seismic data for feature extraction. SN Appl. Sci. 2020, 2, 1-12. [CrossRef]

27. Tary, J.B.; Herrera, R.H.; van der Baan, M. Analysis of time-varying signals using continuous wavelet and synchrosqueezed transforms. Philos. Trans. A Math. Phys. Eng. Sci. 2018, 376, 1-16. [CrossRef]

28. Addison, P.S. Introduction to redundancy rules: The continuous wavelet transform comes of age. Philos. Trans. R. Soc. A Math. Phys. Eng. Sci. 2018, 376, 1-15. [CrossRef] 
29. Costa, M.S.V. Time-space characterization of droughts in the São Francisco river catchment using the Standard Precipitation Index and continuous wavelet transform. Braz. J. Water Resour. 2019, 24, 1-12.

30. Aguiar-Conraria, L.; Soares, M.J.; Sousa, R. California's carbon market and energy prices: A wavelet analysis. Philos. Trans. R. Soc. A Math. Phys. Eng. Sci. 2018, 376, 2126. [CrossRef] [PubMed]

31. Liu, C.Y.; Yao, C.L.; Xiong, J. Geophysical Potential Field Anomaly Separation Method with Optimal Mother Wavelet and Spatial Locating Multiresolution Analysis (MRA). IEEE Access 2019, 7, 62840-62851. [CrossRef]

32. Dziedziech, K.; Nowak, A.; Hasse, A.; Uhl, T.; Staszewski, W.J. Wavelet-based analysis of time-variant adaptive structures. Philos. Trans. R. Soc. A Math. Phys. Eng. Sci. 2018, 376, 2126. [CrossRef] [PubMed]

33. Hadjileontiadis, L.J. Continuous wavelet transform and higher-order spectrum: Combinatory potentialities in breath sound analysis and electroencephalogram-based pain characterization. Philos. Trans. R. Soc. A Math. Phys. Eng. Sci. 2018, 376, 1-16. [CrossRef] [PubMed]

34. de Souza, P.V. Fuzzy neural networks and neuro-fuzzy networks: A review the main techniques and applications used in the literature. Appl. Soft Comput. 2020, 92, 1-26.

35. Manzoor, B.; Othman, I.; Durdyev, S.; Ismail, S.; Wahab, M.H. Influence of Artificial Intelligence in Civil Engineering toward Sustainable Development-A Systematic Literature Review. Appl. Syst. Innov. 2021, 4, 52. [CrossRef]

36. Rajbhandari, Y.; Marahatta, A.; Ghimire, B.; Shrestha, A.; Gachhadar, A.; Thapa, A.; Chapagain, K.; Korba, P. Impact Study of Temperature on the Time Series Electricity Demand of Urban Nepal for Short-Term Load Forecasting. Appl. Syst. Innov. 2021, 4, 43. [CrossRef]

37. Kadam, V.; Kumar, S.; Bongale, A.; Wazarkar, S.; Kamat, P.; Patil, S. Enhancing Surface Fault Detection Using Machine Learning for 3D Printed Products. Appl. Syst. Innov. 2021, 4, 34. [CrossRef]

38. MathWorks. Wine Classification, MathWorks Help Centre. 2021. Available online: https://www.mathworks.com/help/ deeplearning/ug/wine-classification.html (accessed on 6 September 2021).

39. Giap, C.N.; Son, L.H.; Chiclana, F. Dynamic structural neural network. J. Intell. Fuzzy Syst. 2018, 34, 2479-2490. [CrossRef]

40. Gupta, T.K.; Raza, K. Optimizing Deep Feedforward Neural Network Architecture: A Tabu Search Based Approach. Neural Process. Lett. 2020, 51, 2855-2870. [CrossRef]

41. Silva, L.E.B.; Elnabarawy, I.; Wunsch, D.C. Dual Vigilance Adaptive Resonance Theory. Neural Netw. Lett. 2019, 109, 1-6. [CrossRef]

42. Grossberg, S. Adaptive Resonance Theory: How a brain learns to consciously attend, learn, and recognize a changing world. Neural Netw. 2013, 37, 1-47. [CrossRef] [PubMed]

43. da Silva, L.E.B.; Elnabarawy, I.; Wunsch, D.C. A Survey of Adaptive Resonance Theory Neural Network Models for Engineering Applications. Neural Netw. 2019, 120, 167-203. [CrossRef] [PubMed]

44. Dongare, A.D.; Kharde, R.R.; Kachare, A.D. Introduction to Artificial Neural Network. Int. J. Eng. Innov. Technol. 2012, 2, 189-194.

45. Sarmadi, H.; Entezami, A. Application of supervised learning to validation of damage detection. Arch. Appl. Mech. 2020, 91, 393-410. [CrossRef]

46. Keller, J.; Gray, M.; Givens, J. A fuzzy K-nearest neighbor algorithm. IEEE Trans. Syst. Man. Cybern. 1985, 4, 580-585. [CrossRef]

47. UNSW. “Multilayer Perceptron-Backpropagation", University of New South Wales. 2020. Available online: https://www.cse. unsw.edu.au/ \{\}cs9417ml/MLP2/BackPropagation.html (accessed on 6 September 2021).

48. Taud, H.; Mas, J.F. Multilayer Perceptron (MLP). In Geomatic Approaches for Modeling Land Change Scenarios; Springer: Cham, Switzerland, 2018; pp. 451-455.

49. Heidari, A.A.; Faris, H.; Aljarah, I.; Mirjalili, S. An efficient hybrid multilayer perceptron neural network with grasshopper optimization. Soft Comput. 2018, 23, 7941-7958. [CrossRef]

50. Fabietti, M.; Mahmud, M.; Lotfi, A.; Kaiser, S.M.; Averna, A.; Guggenmos, D.J.; Nudo, R.J.; Chiappalone, M.; Chen, J. SANTIA: A Matlab-based open-source toolbox for artifact detection and removal from extracellular neuronal signals. Brain Inform. 2021, 8, 1-19. [CrossRef]

51. MathWorks. Does Patternnet Create MLP Neural Network? MathWorks MATLAB Answers. 2021. Available online: https: //www.mathworks.com/matlabcentral/answers/375425-does-patternnet-create-mlp-neural-network (accessed on 6 September 2021).

52. Žukauskas, P.; Vveinhardt, J.; Andriukaitienè, R. Philosophy and Paradigm of Scientific Research. In Management Culture and Corporate Social Responsibility; IntechOpen: London, UK, 2018; pp. 121-139.

53. Ragab, M.A.; Arisha, A. Research Methodology in Business: A Starter's Guide. Manag. Organ. Stud. 2017, 5, 1-24. [CrossRef]

54. Atieno, O.P. An analysis of the strengths and limitation of qualitative and quantitative research paradigms. Probl. Educ. 21st Century 2009, 13, 13-18.

55. Patel, H.; Thakkar, A.; Pandya, M.; Makwana, K. Neural network with deep learning architectures. J. Inf. Optim. Sci. 2018, 39, 31-38. [CrossRef]

56. Tan, T.; Yang, Z.; Chang, F.; Zhao, K. Prediction of the First Weighting from the Working Face Roof in a Coal Mine Based on a GA-BP Neural Network. Appl. Sci. 2019, 9, 4159. [CrossRef] 